\title{
PENYULUHAN PENDIDIKAN MELALUI KEGIATAN BEDAH FILM DI DESA WANATAWANG KABUPATEN BREBES
}

\author{
Atikah Mumpuni ${ }^{1}$, Ubaedillah ${ }^{2}$, Erika Noviana ${ }^{3}$, Ujiati Cahyaningsih ${ }^{4}$, \\ Dede Salim Nahdi ${ }^{5}$ \\ 1,2,3 Universitas Muhadi Setiabudi, Indonesia \\ 4,5 Universitas Majalengka, Indonesia \\ 1atikahmumpuni@umus.ac.id
}

\begin{abstract}
Education is a provision for adolescents to live in society. However, education awareness is still low and education is often neglected. The film review activity is a breakthrough to be able to provide educational education in a more enjoyable manner. This community service activity was carried out in Wanatawang Village, Songgom District. The target of the activity is youth in Wanatawang Village aged 11-15 years. The method of implementing the activity is carried out through film review, counseling, and mentoring. The results of the activities carried out, namely 1) The film "Jembatan Pinsil" which is used in extension activities, is full of motivation and educational values. Teenagers are very enthusiastic about the film and the motivation in the film inspires them to pursue higher education. 2) The motivation of youth in Wanatawang Village was awakened after counseling and mentoring. This can be seen from the results of the questionnaires that were distributed after the activity was completed. The conclusion that can be written is that educational outreach activities with the help of film reviews and educational assistance are very effective in increasing awareness of Wanatawang Village youth about the importance of education. Suggestions that can be written are that film review activities should be carried out in a sustainable manner, so that the motivation of youth in Wanatawang Village is nurtured to continue their education to a higher level.
\end{abstract}

Keywords: education counseling; film surgery; motivation; higher education

\begin{abstract}
Abstrak
Pendidikan merupakan bekal bagi remaja untuk dapat hidup bermasyarakat. Akan tetapi, kesadaran pendidikan yang masih rendah membuat pendidikan seringkali diabaikan. Kegiatan bedah film merupakan terobosan yang dilakukan untuk dapat memberikan penyuluhan pendidikan dengan lebih menyenangkan. Kegiatan pengabdian kepada masyarakat ini dilaksanakan di Desa Wanatawang, Kecamatan Songgom. Sasaran kegiatan adalah remaja Desa Wanatawang yang berusia antara 11-15 tahun. Metode pelaksanaan kegiatan dilakukan melalui bedah film, penyuluhan, dan pendampingan. Hasil dari kegiatan yang dilaksanakan, yaitu 1) Film 'Jembatan Pinsil' yang digunakan dalam kegiatan penyuluhan, sarat akan motivasi dan nilai-nilai pendidikan. Remaja sangat antusias dalam film tersebut dan motivasi dalam film tersebut menginspirasi remaja untuk menempuh pendidikan yang lebih tinggi. 2) Motivasi remaja di Desa Wanatawang terbangun setelah dilakukan penyuluhan dan pendampingan. Hal ini dapat dilihat dari hasil angket yang dibagikan setelah kegiatan selesai. Simpulan yang dapat dituliskan yaitu, kegiatan penyuluhan pendidikan dengan bantuan bedah film dan pendampingan pendidikan sangat efektif dalam meningkatkan kesadaran remaja Desa Wanatawang akan pentingnya pendidikan. Saransaran yang dapat dituliskan yaitu, kegiatan bedah film sebaiknya dilaksanakan secara berkelanjutan, agar motivasi remaja Desa Wanatawang terpupuk untuk melanjutkan pendidikan ke jenjang yang lebih tinggi.
\end{abstract}

Kata Kunci: penyuluhan pendidikan; bedah film; motivasi; pendidikan tinggi

Submitted: $2020-09-25$

Revised: 2020-10-09

Accepted: 2020-10-04

\section{Pendahuluan}


Pendidikan adalah usaha yang dilakukan secara sadar dan terencana untuk mewujudkan generasi bangsa yang cerdas dan berkepribadian. Hal ini sesuai dengan Undang-Undang Sistem Pendidikan Nasional No. 20 Tahun 2003 yang menyebutkan Pendidikan sebagai usaha sadar dan terencana dalam mewujudkan suasana belajar dan proses pembelajaran agar peserta didik aktif untuk mengembangkan potensi dirinya agar memiliki kekuatan spriritual keagamaan, pengendalian diri, kepribadian, kecerdasan, akhlak mulia, serta keterampilan yang diperlukan dirinya, masyarakat, bangsa, dan negara. Pendidikan yang ditempuh peserta didik nantinya, bukan hanya untuk mengembangkan potensi yang dimilikinya, tetapi juga mengasah keterampilan peserta didik sehingga siap untuk hidup bermasyarakat.

Pendidikan juga akan mengantarkan keberlanjutan hidup manusia di lingkungannya. Hal ini dipertegas oleh Haderani (2018) yang menyebutkan bahwa pendidikan menjadikan manusia dapat menggunakan ilmu pengetahuan secara bijak dan sesuai norma untuk keberlanjutan hidup manusia. Artinya, pendidikan akan menjadi bekal bagi manusia dalam hidup bermasyarakat. Akan tetapi, pentingnya pendidikan bagi kehidupan manusia ini agaknya mulai dilupakan.

Wanatawang adalah salah satu desa di Kecamatan Songgom, Kabupaten Brebes. Seperti kebanyakan desa yang lainnya di Kecamatan Songgom, kesadaran akan pentingnya pendidikan masih terbilang cukup rendah. Hal ini dapat dilihat dari hasil survey yang telah dilakukan dari 40 remaja desa Wanatawang yang dipilih secara acak, 37 diantaranya memilih untuk bekerja daripada melanjutkan sekolah yang lebih tinggi. Alasannya sederhana, saat bekerja, mereka akan mendapatkan uang, yang dapat digunakan untuk memenuhi kebutuhan hidup sehari-hari. Sementara, remaja menganggap pendidikan tidak akan dapat memenuhi kebutuhan hidup sehari-hari.

Padahal pendidikan bukan hanya dapat memenuhi kebutuhan hidup, tetapi akan dapat memperbaiki hidup. Perbaikan hidup yang didapatkan melalui pendidikan tidak secara langsung seketika dapat dirasakan. Akan tetapi, perlu proses dan waktu untuk melihat dan merasakan hasilnya. Oleh sebab itu, kesadaran akan pentingnya pendidikan perlu ditumbuhkan, khususnya bagi remaja di desa Wanatawang.

Kesadaran akan pentingnya pendidikan, dapat ditumbuhkan melalui kegiatan penyuluhan pendidikan. Di Desa Wanatawang, Kecamatan Songgom selama ini juga belum pernah diadakan penyulukan untuk menumbuhkan kesadaran akan pendidikan bagi warga masyarakat, khususnya para remajanya. Oleh sebab itu, penyuluhan pendidikan menjadi hal yang perlu dilakukan bagi remaja di desa Wanatawang.

Penyuluhan pendidikan tentu perlu menggunakan media yang menarik agar kegiatan penyuluhan tersebut dapat diterima oleh masyarakat luas. Salah satu bentuk penyuluhan pendidikan yang menarik untuk dapat dilakukan adalah melalui kegiatan bedah film. Tentu saja film yang disajikan untuk dapat menumbuhkan kesadaran akan pendidikan adalah film-film bertajuk pendidikan. Hal ini juga diperkuat oleh Marwa \& Kamalia (2019) yang menyebutkan bahwa film bertajuk pendidikan dapat menyisipkan nilai-nilai karakter serta pendidikan yang dapat memunculkan sikap positif dalam diri peserta didik.

Salah satu film bertajuk pendidikan yang digunakan dalam kegiatan penyuluhan pendidikan adalah film "Jembatan Pinsil" karya Hasto Broto. Film tersebut menyisipkan pesan moral mengenai semangat dan keinginan anak-anak dalam menggapai pendidikan, 
sifat pantang menyerah, dan harapan untuk menggapai cita-cita (Khairunnisa \& Lokananta, 2018). Film tersebut dapat memberikan contoh nyata bagi remaja di Desa Wanatawang untuk dapat menggapai pendidikan ditengah segala keterbatasan yang ada.

Selanjutnya, perumusan masalah berdasarkan uraian permasalahan mitra dapat dirumuskan: 1) bagaimana pengaruh nilai-nilai pendidikan dalam film 'Jembatan Pensil' dalam memotivasi remaja Desa Wanatawang dari sisi pendidikan?; 2) Bagaimana motivasi remaja Desa Wanatawan untuk melanjutkan ke pendidikan tinggi setelah dilakukan penyuluhan dan pendampingan pemilihan sekolah.

Mengacu pada uraian latar belakang dan rumusan masalah, tujuan kegiatan yang dapat ditulis yaitu: 1) Untuk mengetahui pengaruh nilai-nilai pendidikan dalam film 'Jembatan Pensil' dalam memotivasi remaja Desa Wanatawang dari sisi pendidikan; 2) untuk mengetahui motivasi remaja Desa Wanatawan dalam melanjutkan ke pendidikan tinggi setelah dilakukan penyuluhan dan pendampingan pemilihan sekolah.

\section{Metode}

Sasaran kegiatan ini adalah remaja di Desa Wanatawang yang berusia antara 11 sampai dengan 15 tahun. Lokasi kegiatan dilaksanakan di Desa Wanatawang, Kecamatan Songgom, Kabupaten Brebes. Kegiatan pengabdian kepada masyarakat yang dilakukan ini, mengkolaborasikan tiga metode, yaitu bedah film, penyuluhan pendidikan, dan pendampingan. Film-film yang disajikan dalam kegiatan bedah film adalah film-film yang bertajuk pendidikan. Hal ini dilakukan dengan harapan, nilai-nilai pendidikan yang ada didalam film dapat memotivasi remaja di Desa Wanatawang untuk melanjutkan pendidikan ke jenjang yang lebih tinggi.

Rangkaian kegiatan yang dilaksanakan setelah kegiatan bedah film adalah penyuluhan pendidikan. Materi yang disampaikan dalam kegiatan penyuluhan pendidikan, yaitu urgensi pendidikan bagi generasi muda dan motivasi untuk dapat melanjutkan ke jenjang pendidikan yang tinggi. Terakhir, kegiatan pendampingan memilih sekolah pada pada jenjang yang lebih tinggi dilakukan oleh tim mahasiswa yang telah ditunjuk oleh kampus sebagai bentuk tindak lanjut dari kegiatan penyuluhan pendidikan. Ketercapaian tujuan kegiatan pengabdian kepada masyarat yang dilaksanakan di Desa Wanatawang diukur melalui angket motivasi pendidikan yang diberikan setelah pelaksanaan kegiatan pengabdian selesai.

\section{Hasil dan Pembahasan}

1. Nilai-Nilai Pendidikan dalam Film 'Jembatan Pinsil' dan Motivasi Pendidikan Remaja Desa Wanatawang Kecamatan Songgom Kabupaten Brebes

Film merupakan media yang efektif untuk menyampaikan pesan kepada penontonnya. Film akan menyajikan audio, visual, dan audio-visual secara bersamaan, sehingga memanjakan penontonnya. Hal ini karena film dapat dapat memfasilitasi siswa sesuai dengan gaya belajarnya. Muslich (2010: 104) mengemukakan tiga gaya belajar siswa yaitu, "Gaya belajar visual, auditori, dan kinestetik."

Gaya belajar visual lebih menekankan pada pengelihatan, gaya belajar auditori lebih menekankan pada pendengaran. Sementara itu, gaya belajar kinestetik menekankan 
pada gerakan untuk melakukan sesuatu dari informasi yang diterimanya. Media sebagai penyalur pesan hendaknya dipilih sesuai dengan gaya belajar siswa, sehingga siswa akan lebih mudah memahami pelajaran. Dengan demikian, dapat dikatakan bahwa pemilihan film adalah hal yang perlu dilakukan untuk dapat memfasilitasi siswa sesuai dengan kebutuhannya.

Film-film bertajuk pendidikan yang dapat meningkatkan minat dan motivasi, serta kesadaran siswa akan pendidikan, diantaranya: 1) Sekolah Rimba; 2) Sang Pemimpi; 3) 3-idiot; 4) Sepatu Dahlan; 5) Jembatan Pinsil; dll. Dalam hal ini 'Jembatan Pinsil' dipilih sebagai media yang digunakan dalam penyuluhan pendidikan di Desa Wanatawang, Kecamatan Songgom, Kabupaten Brebes.

Film "Jembatan Pinsil" adalah salah satu film yang bertajuk pendidikan. Film ini menceritakan tentang perjuangan anak-anak usia Sekolah Dasar (Inal, Nia, Aska, Yanti, dan Ondeng) untuk terus bersekolah di sebuah sekolah gratis yang dibangun oleh Pak Guru. Perjalanan mereka untuk sampai ke sekolah bukanlah perkara mudah. Banyak jalanan terjal dan berbahaya yang harus ditempuh.

Seandainya saja anak-anak itu tidak menyadari pentingnya pendidikan dan sekolah, sudah barang pasti anak-anak itu tidak akan melanjutkan sekolah. Terlebih, kondisi Inal yang tuna netra dan Ondeng yang memiliki 'keterbelakangan', tentu bukan perkara mudah. Namun, anak-anak ini menyadari betul pentingnya pendidikan dan sekolah untuk mereka. Sehingga semua anak-anak ini tetap dapat menikmati masa-masa sekolah dengan gembira walaupun harus melalui perjalanan yang berbahaya untuk berangkat dan pulang sekolah.

Jembatan pinsil adalah konsep jembatan yang dibuat oleh Ondeng agar temantemannya dapat melewati jembatan dengan aman untuk bersekolah. Hal ini karena kondisi jembatan yang dilewati oleh teman-teman Ondeng sudah tua dan lapuk, sewaktuwaktu bisa putus. Semangat anak-anak ini bersekolah tidak lepas dari peran orang tua, lingkungan, dan guru. Konsep pendidikan yang lakukan oleh orang tua anak-anak itu adalah fokus pada tumbuh kembang anaknya. Bukan fokus pada tumbuh kembang anak lain, yang biasa kita jumpai di lingkungan. Fokus dengan tumbuh kembang anak akan membangun kepercayaan diri yang kuat dan memupuk semangat belajar, serta memunculkan kesadaran akan pendidikan untuk terus bersekolah.

Semangat untuk bersekolah, juga didukung karena lingkungan sekitarnya. Uniknya diceritakan dalam film tersebut, keterbatasan yang ada justru membuat anak-anak semangat untuk belajar, karena ingin memenuhi fasilitas di lingkungannya, seperti fasilitas kesehatan, fasilitas pendidikan, dll. Hal ini tentu bukan berarti kita membinasakan fasilitas yang ada untuk dapat meningkatkan minat belajar siswa. Justru sebaliknya, dengan fasilitas yang sudah serba ada seperti sekarang ini, seharusnya belajar akan menjadi lebih fokus dan dapat menghasilkan hasil yang maksimal.

Peran guru juga turut andil dalam meningkatkan semangat belajar siswa. Seandainya guru membatasi siswa, tidak memperkenankan siswa yang berkebutuhan khusus untuk belajar, tentu akan lain ceritanya. Pak guru yang diceritakan dalam film ini membuat anak-anak tersebut dapat menikmati masa Sekolah Dasarnya dengan keceriaan serta mengajarkan sikap saling menghargai, sehingga dapat menerima dan berteman dengan temannya yang berkebutuhan khusus. Kesimpulan yang dapat diambil dari film 'Jembatan Pinsil' adalah bahwa untuk mendukung keberhasilan pendidikan perlu adanya 
kerja sama yang baik antara orang tua, sekolah, dan lingkungan. Keberhasilan pendidikan tentu tidak dapat diliihat dalam sekejap mata, tetapi dapat dilihat dari tingginya minat siswa untuk sekolah.

Setelah dilaksanakan kegiatan penyuluhan yang berbantuan bedah film bertajuk pendidikan, remaja Desa Wanatawang terlihat sangat antusias untuk dapat melanjutkan pendidikannya. Hal ini terlihat dari raut wajah serta semangat remaja Desa Wanatawang. Nilai-nilai pendidikan dalam film "Jembatan Pensil" dapat menjadi inspirasi bagi remaja di Desa Wanatawang untuk dapat melanjutkan pendidikan apapun kendala yang dihadapi. Setelah dilakukan penyuluhan pendidikan dan bedah film, remaja Desa Wanatawang juga termotivasi untuk terus belajar menggapai cita-cita dan impian. Disamping itu, antusia

2. Motivasi untuk Melanjutkan ke Pendidikan Tinggi Pendampingan Pemilihan Sekolah untuk Jenjang yang Lebih Tinggi

Motivasi untuk melanjutkan pendidikan yang lebih tinggi, tentu sangat dipengaruhi pemaknaan pendidikan bagi siswa itu sendiri. Dewantara (1973: 14) menyebutkan bahwa, "Pendidikan adalah daya upaya untuk memajukan tumbuhnya budi pekerti (kekuatan batin, karakter), pikiran, dan pertumbuhan siswa." Dengan menyadari bahwa pendidikan akan menumbuhkan budi pekerti yang baik, cara berpikir yang luas, dan perkembangan pada siswa itu sendiri, seharusnnya siswa dapat menyadari pentingnya pendidikan, sehingga termotivasi untuk melanjutkan pendidikan ke jenjang yang lebih tinggi.

Pendidikan erat kaitannya dengan belajar. Sagala (2011: 50) menyebutkan bahwa, "Belajar adalah adanya perubahan kematangan bagi siswa sebagai akibat dari adanya interaksi antara pendidik dan peserta didik dalam proses pembelajaran." Belajar dalam arti sempit memang terbatas pada ruang kelas. Akan tetapi, belajar dalam arti luas sesungguhnya adalah konsep belajar seumur hidup. Konsep belajar seumur hidup ini diakukan agar terjadi kematangan dalam diri siswa sehingga siap hidup bermasyarakat. Motivasi untuk melanjutkan ke pendidikan tinggi tentu saja perlu ditumbuhkan melalui berbagai cara diantaranya: 1) dengan memaknai hakikat pendidikan; 2) kesadaran untuk belajar seumur hidup; 3) kemauan untuk menjadi pribadi dengan wawasan yang luas dan berkarakter sebagai bekal hidup bermasyarakat.

Selanjutnya, pemilihan sekolah yang tepat seharusnya menjadi perhatian semua elemen masyarakat. Jangan sampai remaja salah memilih sekolah hingga berujung putus sekolah. Pemilihan sekolah perlu disesuaikan dengan minat, bakat, dan kemampuan siswa atau remaja. Pemilihan sekolah yang sesuai dengan ketiga hal tersebut, tentu akan meningkatkan motivasi remaja untuk terus bersekolah. Pendampingan pemilihan sekolah untuk jenjang yang lebih tinggi dibantu oleh mahasiswa dengan mencari tahu terlebih dahulu minat dan bakan remaja, kemudian mengusulkan sekolah yang tepat. Kegiatan ini diharapkan dapat memberikan kontribusi nyata kepada masyarakat untuk mendukung pendidikan tinggi bagi warganya.

\section{Kesimpulan}

Kesimpulan dari kegiatan ini yaitu, penyuluan pendidikan melalui kegiatan bedah film efektif dalam meningkatkan kesadaran remaja desa Wanatawang untuk melanjutkan pendidikan ke jenjang yang lebih tinggi. Disamping itu, kegiatan ini juga membawa dampak yang cukup baik dalam meningkatkan kesadaran pendidikan bagi remaja Desa 
Wanatawang. Saran dari kegiatan penyuluhan pendidikan melalui kegiatan bedah film adalah kegiatan bedah film itu sebaiknya perlu dilaksanakan secara berkelanjutan agar motivasi remaja terus terpupuk untuk melanjutkan pendidikan ke jenjang yang lebih tinggi.

\section{Daftar Pustaka}

Dewantara, K.H. (1973). Bagian Pertama Pendidikan. Yogyakarta: Majelis Luhur Persatuan Taman Siswa

Haderani, H. (2018). Tinjauan Filosofis tentang Fungsi Pendidikan dalam Hidup Manusia. Jurnal Tarbiyah: Jurnal Ilmiah Kependidikan, オ1), 41-49. https://doi.org/10.18592/tarbiyah.v7i1.2103

Khairunnisa, F., \& Lokananta, A. C. (2018). Analisis Pesan Moral Pada Film 'Jembatan Pantarei, 4 https://jom.fikom.budiluhur.ac.id/index.php/Pantarei/article/view/545

Marwa, A., \& Kamalia, N. (2019). Representasi Pendidikan Karakter di Film Dua Garis Biru Berdasarkan Perspektif Thomas Lickona. Prosiding Konferensi Pendidikan Nasional "Strategi Dan Implementasi Pendidikan Karakter Pada Era Revolusi Industri 4.0" ISSN:, ISSN: 26548607, 32-41.

Muslich, M. (2010). Text Book Writing: Dasar-Dasar Pemahaman, Penulisan, Dan Pemakaian Buku Teks. Yogyakarta: Ar-Ruzz Media

Sagala, S. (2011). Konsep dan Makna Pembelajaran. Bandung: Alfabeta

Undang-Undang Sistem Pendidikan Nasional No. 20 Tahun 2003, tentang Sistem Pendidikan Nasional 